\title{
REMOVAL OF CATIONIC TEXTILE DYE METHYLENE BLUE (MB) USING STEEL SLAG COMPOSITE
}

\author{
J. Baalamurugan ${ }^{1,2}$, V. Ganesh Kumar ${ }^{1, *}$, B. S. Naveen Prasad ${ }^{3}$ \\ and K. Govindaraju ${ }^{1}$ \\ ${ }^{1}$ Centre for Ocean Research (DST-FIST Sponsored Centre), Sathyabama Institute of Science and \\ Technology, Chennai-600 119, Tamil Nadu, India. \\ ${ }^{2}$ Department of Chemistry, Sathyabama Institute of Science and Technology, Chennai-600 119, \\ Tamil Nadu, India. \\ ${ }^{3}$ Chemical Section, Salalah College of Technology, Thumrait Rd. Salalah, Dhofar, Oman -211. \\ *E-mail: ganeshkumar@sathyabama.ac.in
}

\begin{abstract}
Steel slag is generated during the steel production of around10-15\% per tonne. Steel slag composite has various metal oxides mainly composed of iron, aluminum, manganese and calcium along with silica. Dyes of textile industry effluent are one of the major threats to the environment. Methylene Blue (MB) a cationic dye originated from various dyeing processes of textile industries. In this research work, Induction Furnace (IF) steel slag is utilized in the removal of cationic textile dye Methylene Blue (MB). Steel slag materials were thermally activated at $600^{\circ} \mathrm{C}$ for $4 \mathrm{hrs}$. UV-Vis spectroscopy is used to determine the removal properties of IF steel slag on MB dye. Adsorbent dosage, initial dye concentration and $\mathrm{pH}$ with various contact time were studied. Surface morphology and structural bonding of steel slag materials over dye molecule were studied using Scanning Electron Microscope (SEM) and Fourier Transform Infrared (FTIR) analysis respectively. The removal mechanism of textile dye (MB) using industrial by-product slag composite has been explored.
\end{abstract}

ABSTRACT

Keywords: Steel Slag, Methylene Blue, Core-shell Formation, Dye Removal, Wastewater Treatment.

(C) RASĀYAN. All rights reserved

\section{INTRODUCTION}

Steel slag an industrial by-product during the steel manufacturing process and is generated nearly $10-15 \%$ in the manufacture of one ton steel ${ }^{1}$. Due to globalization, the production of steel is increasing and so the slag. Steel slag applications include concrete, ${ }^{2-6}$ radiation shielding, ${ }^{7,8}$ heavy metal removal, ${ }^{1,9}$ fire resistance, ${ }^{10}$ agriculture, ${ }^{11}$ coral rehabilitation ${ }^{12}$ and $\mathrm{CO}_{2}$ sequestration ${ }^{13}$. Prevention of water bodies from pollution and toxicity is a major responsibility during the promotion of industrialization. Textile dye pollution is a huge threat to water bodies ${ }^{14}$ and its living species in the ecosystem by disturbing their growth and causes serious health issues. Generally, the discharge from industries is directed to the nearest water source ${ }^{15}$. Industries such as textiles, leather, plastics and other relevant industries use various dyes to impart color in products and also consume the substantial volume of water ${ }^{16}$ which ends up with colored wastewater being discharged into the environment and causing water pollution ${ }^{17}$. Various industries using different dyes hurt living organisms within short exposure periods ${ }^{18}$. Throughout the world, approximately $7 \times 10^{5}$ tones of 10,000 types of dyestuff are produced every year ${ }^{19}$. In the textile industry dyeing process, $10-15 \%$ of the unutilized/uncoated dye is discharged as dye effluents ${ }^{20}$ and affecting water bodies. Wastewater treatment studies have been done already by researchers using steel slag $^{21-23}$ to reduce the toxicity level in water bodies.

Methylene Blue a cationic textile dye is widely used for dyeing fabrics and various techniques to remove MB in wastewater were employed. $\mathrm{LiFe}\left(\mathrm{WO}_{4}\right)_{2}$ a heterogeneous Fenton-like catalyst used decolorizes wastewater containing $\mathrm{MB}^{24}$. Dried sewage sludge has been treated at $200^{\circ} \mathrm{C}-700^{\circ} \mathrm{C}$ for the adsorption of $\mathrm{MB}$ dye and the maximum adsorption was recorded at $700^{\circ} \mathrm{C}^{25} . \mathrm{H}_{2} \mathrm{SO}_{4}$ and $\mathrm{Fe}_{3} \mathrm{O}_{4}$ combined chitosan

Rasayan J. Chem., 13(2), 1014-1021(2020)

http://dx.doi.org/10.31788/RJC.2020.1325715

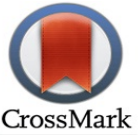


RASĀYAN J. Chem.

Vol. 13 | No. 2 |1014 - 1021| April - June | 2020

adsorbent is prepared for the removal of $\mathrm{MB}$ and the adsorption was effective where the compositions of $0.35 \mathrm{~g}$ chitosan, $0.5 \mathrm{~g} \mathrm{Fe}_{3} \mathrm{O}_{4}$ and $0.02 \mathrm{M} \mathrm{H}_{2} \mathrm{SO}_{4}{ }^{26}$. The behavior of $\mathrm{MB}$ over bentonite clay is studied and the adsorbent removed $95 \%$ of $\mathrm{MB}$ with spontaneous nature of adsorption $\left(-\Delta \mathrm{G}^{\circ}\right)^{27}$. Porous carbon derived from tea waste precursors under thermochemical condition using phosphoric acid acts as an activating agent and the maximum adsorption capacity of tea waste was found over MB was $402.25 \mathrm{mg} \mathrm{g}^{-128 .}$ Decomposition of MB was studied using sodium persulfate in the presence of microwave irradiation (MWI) and the maximum decomposition were obtained $99.9 \%$ for $50 \mathrm{mg} \mathrm{L}^{-1}$ dye concentration, where the time and temperature were kept 8 min and $90^{\circ} \mathrm{C}$ respectively ${ }^{29}$. Also, $\mathrm{MB}$ was removed using diatomite modified with $\mathrm{BaCl}_{2}{ }^{30}$ and terrestrial weeds ${ }^{31}$. Induction Furnace steel slag is not used in cement production due to less calcium and this study is an initiative to effectively utilize IF steel slag due to high iron content. Though various steel slag materials have been used for dye removal, to the best of our knowledge this is the first report in the utilization of IF steel slag for the removal of dyes. In the present study, thermally activated industrial by-product slag $\left(600^{\circ} \mathrm{C}\right.$ for $\left.4 \mathrm{hrs}\right)$ has been utilized for the removal of textile industry cationic dye Methylene Blue from synthetic aqueous solution.

\section{EXPERIMENTAL}

\section{Preparation of Steel Slag Composite}

Induction Furnace steel slag samples were obtained from Jeppiaar furnace and Steels Pvt. Ltd., Kanchipuram, Tamilnadu, India. The size of the slag used in the present study is less than 90 micron $(\mu)$ and it is achieved by the continuous ball milling process. The steel slag sample is washed with deionized water for the removal of surface impurities. The washed steel slag samples were dried in a hot air oven at $200^{\circ} \mathrm{C}$. The dried IF steel slag samples were thermally activated at $600^{\circ} \mathrm{C}$ for $4 \mathrm{hrs}$ and further kept in a desiccator until used for experimental studies. IF steel slag $(<90 \mu)$ utilized in the present study is shown in Fig.-1.

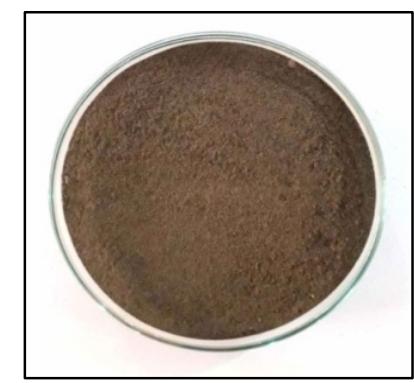

Fig.-1: Induction Furnace Steel Slag Composite

\section{Preparation of Synthetic Dye Solution}

Methylene Blue (MB) was procured from SRL chemicals, India (AR grade). The dye is used without further purification throughout the study. Stock solutions were prepared by dissolving the required quantity of dye in de-ionized water. Various concentrations of dye solutions were prepared and $\mathrm{HCl}$ $(0.1 \mathrm{M}) / \mathrm{NaOH}(0.1 \mathrm{M})$ was used to adjust $\mathrm{pH}$ of the solution.

\section{Techniques Involved}

Surface morphology of IF steel slag before and after removal of dyes was studied using high-resolution scanning electron microscopy (HR-SEM, Hitachi S-4800). The composition of metal oxides present in IF steel slag was determined by using X-ray fluorescence spectroscopy (XRF, Bruker S8 Tiger) analysis. Structural bonding of IF steel slag before and after adsorption were determined using Fourier Transform Infrared Spectroscopy (FTIR, IRAffinity-1S Shimadzu) to identify the changes in the functional group of the sample (4000 to $500 \mathrm{~cm}^{-1}$ ). The samples were prepared as pellets using hydraulic pelletizer, the ratio of sample and $\mathrm{KBr}$ is 1:10 respectively. Removal of $\mathrm{MB}$ was studied using absorption values of supernatant before and after the removal process by UV spectrophotometer (Shimadzu UV-800). 


\section{Dye Decolorization Studies}

The experimental studies were carried out in $250 \mathrm{~mL}$ conical flasks with a known initial dye concentration of $100 \mathrm{~mL}$ dye solution. The sorption system is allowed to reach equilibrium using orbital shaker at $120 \mathrm{rpm}$ and $28^{\circ} \mathrm{C}$ in different contact times. Supernatants were collected for removal studies at regular time intervals. Maximum absorption $\left(\lambda_{\max }\right)$ of MB has been fixed at $663 \mathrm{~nm}$ in a UV spectrophotometer. The removal efficiency of IF steel slag were determined by the following equation:

Removal \% $=\left[\left(\mathrm{C}_{0}-\mathrm{C}_{\mathrm{e}}\right) / \mathrm{C}_{0}\right] \times 100$

Where, $\left(\mathrm{C}_{0}\right)$ and $\left(\mathrm{C}_{\mathrm{e}}\right)$ is the initial and residual dye concentrations $\left(\mathrm{mg} \mathrm{L}^{-1}\right)$, respectively.

Quantity of adsorbed dyes at equilibrium was calculated from the following equation,

$$
\mathrm{q}_{\mathrm{e}}=\left[\left(\mathrm{C}_{0}-\mathrm{C}_{\mathrm{e}}\right) \mathrm{V}\right] / \mathrm{W}
$$

Where, $\mathrm{C}_{0}$ is the initial concentration $\left(\mathrm{mg} \mathrm{L}^{-1}\right), \mathrm{C}_{\mathrm{e}}$ is the dye concentration at various time intervals $\left(\mathrm{mg} \mathrm{L}^{-1}\right), \mathrm{V}$ is the volume of experimental solution $\left(\mathrm{mg} \mathrm{L}^{-1}\right)$ and $\mathrm{W}$ is the weight of IF steel slag $(\mathrm{g})$. The experimental study is performed in triplicate (identical conditions) and the average values were taken for further studies.

\section{Characterization of Steel Slag Composite}

\section{RESULTS AND DISCUSSION}

Elemental composition of IF steel slag has been determined using Energy Dispersive X-Ray Analysis (EDAX) and is given in Table-1. Silicon, iron, aluminum and calcium are the elements present in IF steel slag. Chemical composition of IF steel slag has been analyzed using XRF and is listed in Table-2. $\mathrm{SiO}_{2}$, $\mathrm{Fe}_{2} \mathrm{O}_{3}, \mathrm{Al}_{2} \mathrm{O}_{3}, \mathrm{MnO}$ and $\mathrm{CaO}$ are the major oxides present in IF steel slag with some traces.

Table-1: Elemental Composition of Steel Slag Composite

\begin{tabular}{c|c|c|c|c|c}
\hline Element & $\begin{array}{c}\text { App } \\
\text { Conc. }\end{array}$ & $\begin{array}{c}\text { Intensity } \\
\text { Conc. }\end{array}$ & Weight\% & $\begin{array}{c}\text { Weight\% } \\
\text { Sigma }\end{array}$ & Atomic\% \\
\hline $\mathrm{O}$ & 7.53 & 1.2403 & 42.58 & 1.89 & 62.12 \\
\hline $\mathrm{Al}$ & 0.92 & 0.8529 & 7.59 & 0.71 & 6.57 \\
\hline $\mathrm{Si}$ & 3.02 & 0.8645 & 24.58 & 1.21 & 20.43 \\
\hline $\mathrm{Ca}$ & 0.28 & 1.0009 & 1.99 & 0.55 & 1.16 \\
\hline $\mathrm{Fe}$ & 2.80 & 0.8442 & 23.27 & 1.78 & 9.72 \\
\hline Totals & & & 100.00 & & \\
\hline
\end{tabular}

Table-2: Compounds Present in Steel Slag Composite

\begin{tabular}{c|c}
\hline Formula & Concentrations (\%) \\
\hline $\mathrm{SiO}_{2}$ & 43.22 \\
\hline $\mathrm{Fe}_{2} \mathrm{O}_{3}$ & 28.09 \\
\hline $\mathrm{Al}_{2} \mathrm{O}_{3}$ & 14.46 \\
\hline $\mathrm{MnO}$ & 4.32 \\
\hline $\mathrm{CaO}$ & 2.97 \\
\hline $\mathrm{Cr}_{2} \mathrm{O}_{3}$ & 1.62 \\
\hline $\mathrm{TiO}$ & 1.14 \\
\hline $\mathrm{MgO}$ & 0.97 \\
\hline $\mathrm{Na}_{2} \mathrm{O}$ & 0.75 \\
\hline
\end{tabular}

\section{Impact of Parameters on Textile Dye MB Removal}

In basic $\mathrm{pH}$, metal oxide in solution forms an aqua complex, yielding a negatively charged surface. In the basification process $(\mathrm{NaOH})$ metal ions in IF steel slag such as $\mathrm{Fe}, \mathrm{Al}$ and $\mathrm{Ca}$ tend to form metal hydroxides associated with $\mathrm{Na}^{+}$ions. The $\mathrm{Na}^{+}$ions will subsequently lead to an exchange of cationic dye. Adsorption studies carried out between 4 to $8 \mathrm{pH}$ and the other parameters were kept constant 


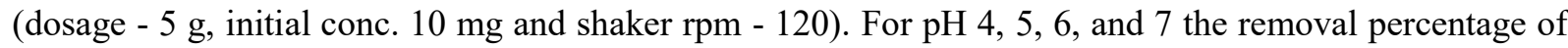
MB dye is $60.96,68.04,74.20$, and 79.45 respectively. The maximum sorption of cationic dye MB (81.28\%) occurs at $\mathrm{pH} 8$ (Fig.-2). The number of possible cationic exchanging site increases the efficiency of MB dye removal via the ion exchange process.

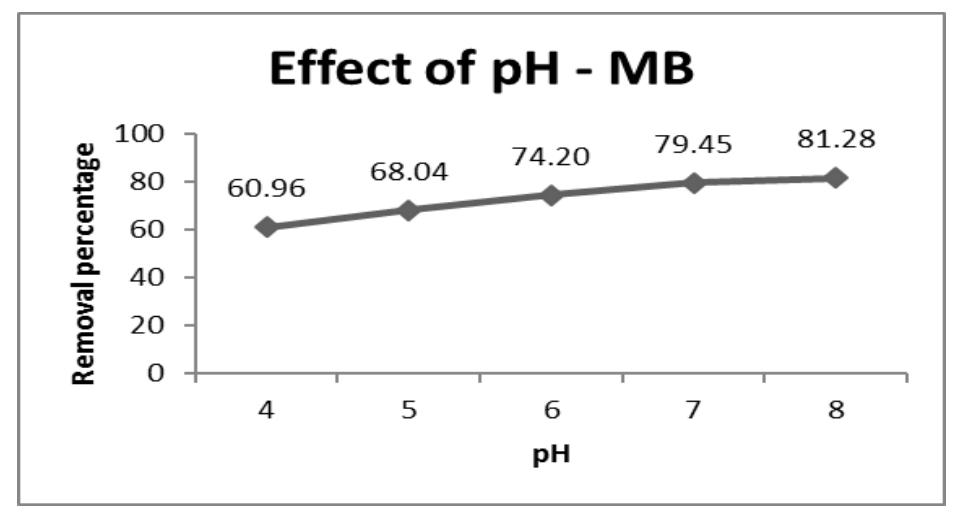

Fig.-2: Effect of pH in Dye Removal Efficiency of Steel Slag Composite

The effect of initial dye concentration of MB is shown in Fig.-3. The decrease in removal percentage of $\mathrm{MB}$ is observed by increasing initial $\mathrm{MB}$ concentration $\left(10-50 \mathrm{mg} \mathrm{L}^{-1}\right)$. The rate of $\mathrm{MB}$ dye removal is rapid and the adsorption is $78.02,74.20,68.22$ and $59.54 \%$. The maximum removal of MB dye (10 mg L $\mathrm{m}^{-1}$ ) is $80.29 \%$ at $\mathrm{pH}-8$ and is observed at 60 min resulting in complex formation, beyond that saturation occurs due to the nonavailability of metal ions in the reaction mixture. The graph is plotted for different concentrations $(10-50 \mathrm{mg})$ for 90 minutes and the decolorization percentage is shown in Fig.-4. At higher dye concentration, the greater number of $\mathrm{MB}$ molecules quickly exchange cations and this process causes a decrease in the percentage removal of further MB due to the limited exchanging ions on the surface of IF steel slag.

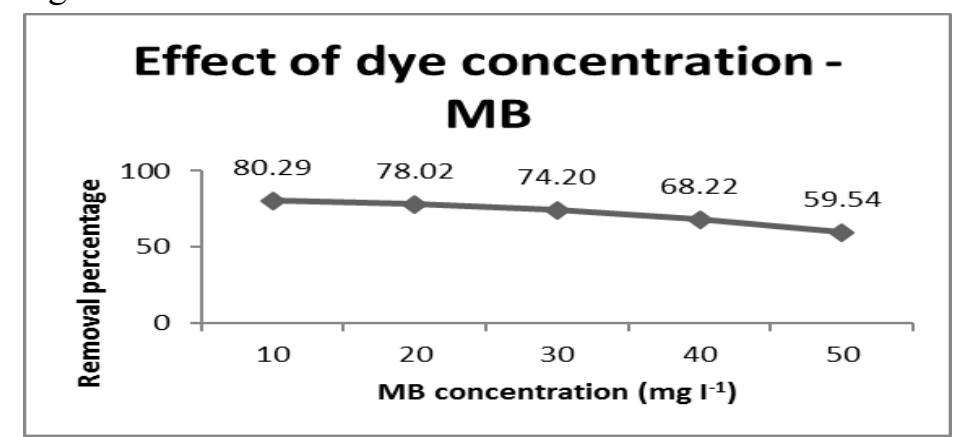

Fig.-3:Effect of the Initial Concentration of Dye Solution in the Removal Efficiency of Steel Slag Composite

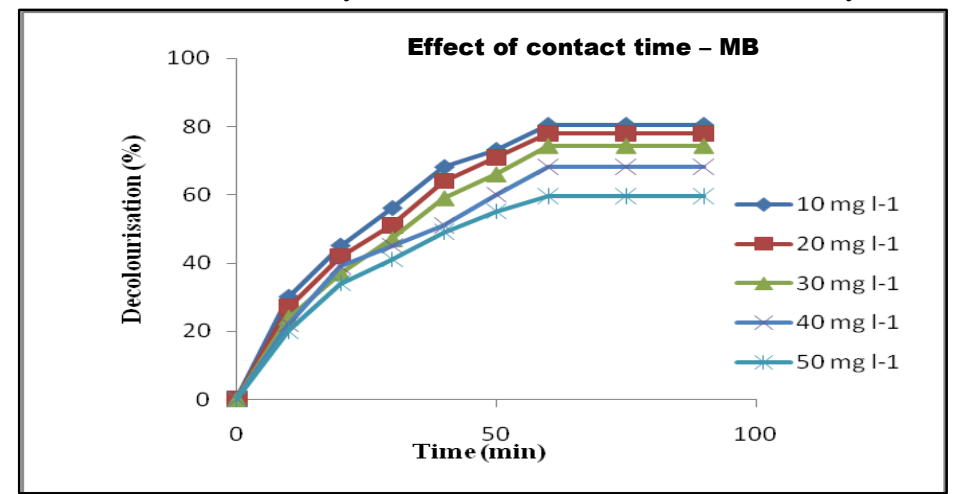

Fig.-4: Effect of Contact Time in the Removal Efficiency of Steel Slag Composite 
The experimental results indicate that, an increase in the dosage of IF steel slag leads to maximum removal of MB dye and is shown in Fig.-5. Adsorption increased from $62.08 \%$ to $80.26 \%$ when the dosage of IF steel slag is increased from 1 to $5 \mathrm{~g}$. The observed enhancement of adsorption of dye is due to an increase in the number of possible cationic exchanging sites of the adsorbent.

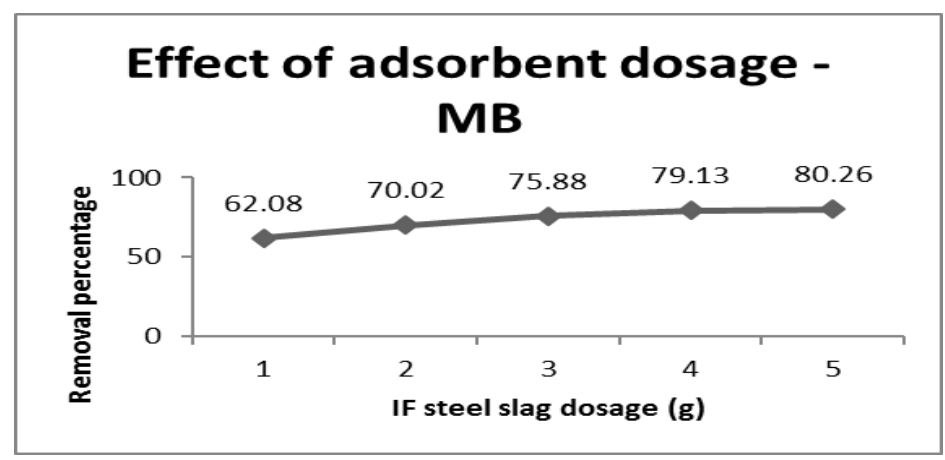

Fig.-5: Effect of Steel Slag Composite Dosage in the Removal of Dye Solution

\section{Mechanism of Dye Removal on Steel Slag Composite}

A mixture of metal oxides present in IF steel slag tends to exchange its metal ions to MB dye molecules. $\mathrm{pH}$ of the reaction mixture is a major factor in the removal of dyes via the cationic exchange of metal ions present in IF steel slag. Due to the large surface area/metal ions in IF steel slag, the higher dosage of adsorbent increases the removal. An increase in $\mathrm{pH}$ of the reaction mixture leads to the formation of the negatively charged surface and favors the textile cationic dye (MB) removal. The number of possible cationic exchanging site increases the efficiency of dye removal via the ion exchange process. The possible mechanism vis ion exchange of MB textile dye with IF steel slag metal ions are as follows:

$$
\mathrm{M} \stackrel{\mathrm{NaOH}}{\longrightarrow} \mathrm{M}-\mathrm{OH}^{-} / \mathrm{Na}^{+}+\mathrm{Dye}^{+} \longrightarrow \mathrm{M}-\mathrm{OH}^{-} / \mathrm{Dye}^{+}+\mathrm{Na}^{+}
$$

\section{Adsorption Characterization of Slag Composite}

SEM images of IF steel slag before adsorption reveals that the surface morphological features and surface characteristics of IF steel slag (Fig.-6). Various shapes and sizes of the elements/particles present in IF steel slag inferred from the SEM image. EDAX analysis of IF steel slag is shown in Table. 2 and the elements present in IF steel slag are in oxide forms of $\mathrm{Si}-24.58 \%$, Fe-23.27\%, Al-7.59\% and $\mathrm{Ca}-1.99 \%$. These metal oxides tend to form metal hydroxides $\left.\left[\mathrm{M}^{\mathrm{x}}(\mathrm{OH})_{\mathrm{y}}\right]\right)$ in aqueous solution. The formation of positive or negative ions on the surface of steel slag is caused by the acidic or basic dissociation via solidsolution interface ${ }^{32}$. Fig.-7 shows the surface morphology of IF steel slag after the dye (MB) removal. SEM images infer that, dye molecules in aqueous solutions are exchanged with its cation and are adsorbed on the surface of IF steel slag leading to the formation of core-shell structure.

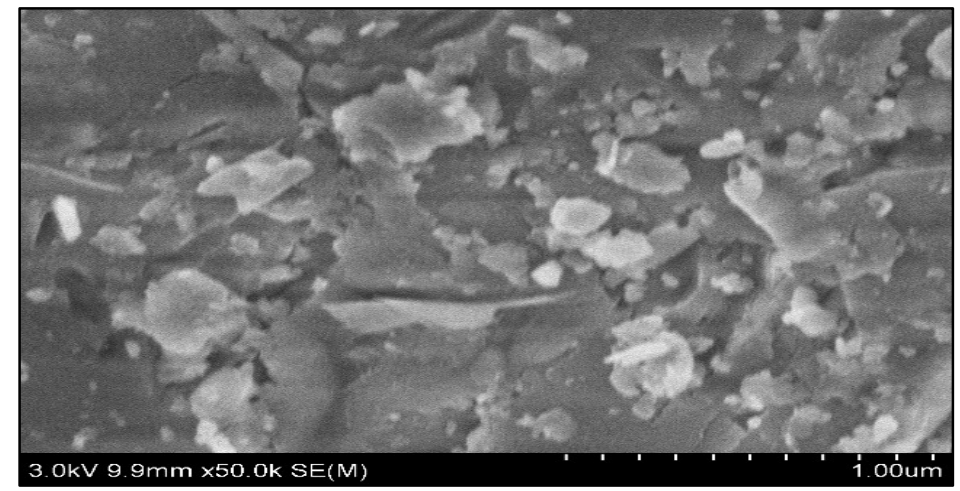

Fig.-6: Surface Morphology of Steel Slag Composite

1018 
RASĀYAN J. Chem.

Vol. 13 | No. 2 |1014 - 1021| April - June | 2020

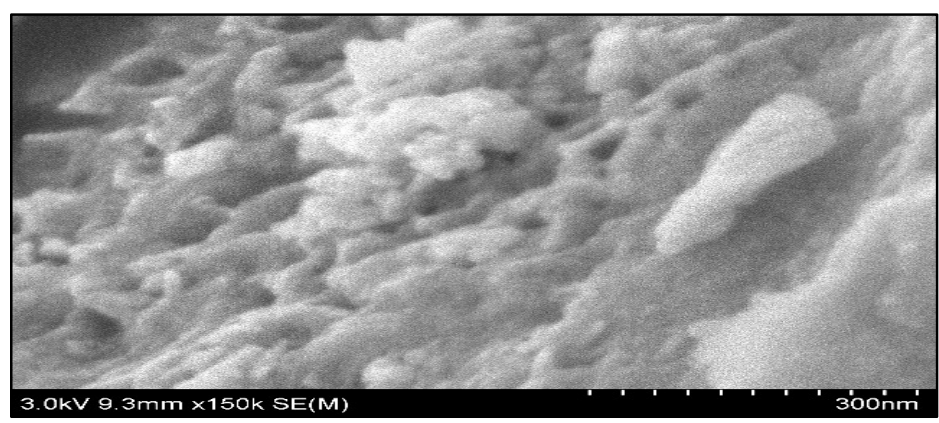

Fig.-7: Steel Slag Surface Morphology after MB Dye Removal

Figure-8 shows the FTIR spectrum of IF steel slag. Major peaks appeared in the spectrum are 3315, 2924, $2374,1664,1402,1116,651,601$, and $464 \mathrm{~cm}^{-1}$. Figure-9 shows the FTIR spectrum of adsorbent after the adsorption of MB dye. The major peaks that appeared in the spectrum are 3315, 3197, 2360, 1670, 1402, 1097, 794, 601 and $462 \mathrm{~cm}^{-1}$. The peaks 1602, 1116 and $835 \mathrm{~cm}^{-1}$ are shifted to 1670,1097 and $794 \mathrm{~cm}^{-1}$ respectively. The peaks from the region 1670 to $1402 \mathrm{~cm}^{-1}$ have been disappeared due to strong adsorption of MB dye on the surface of IF steel slag in basic environment.

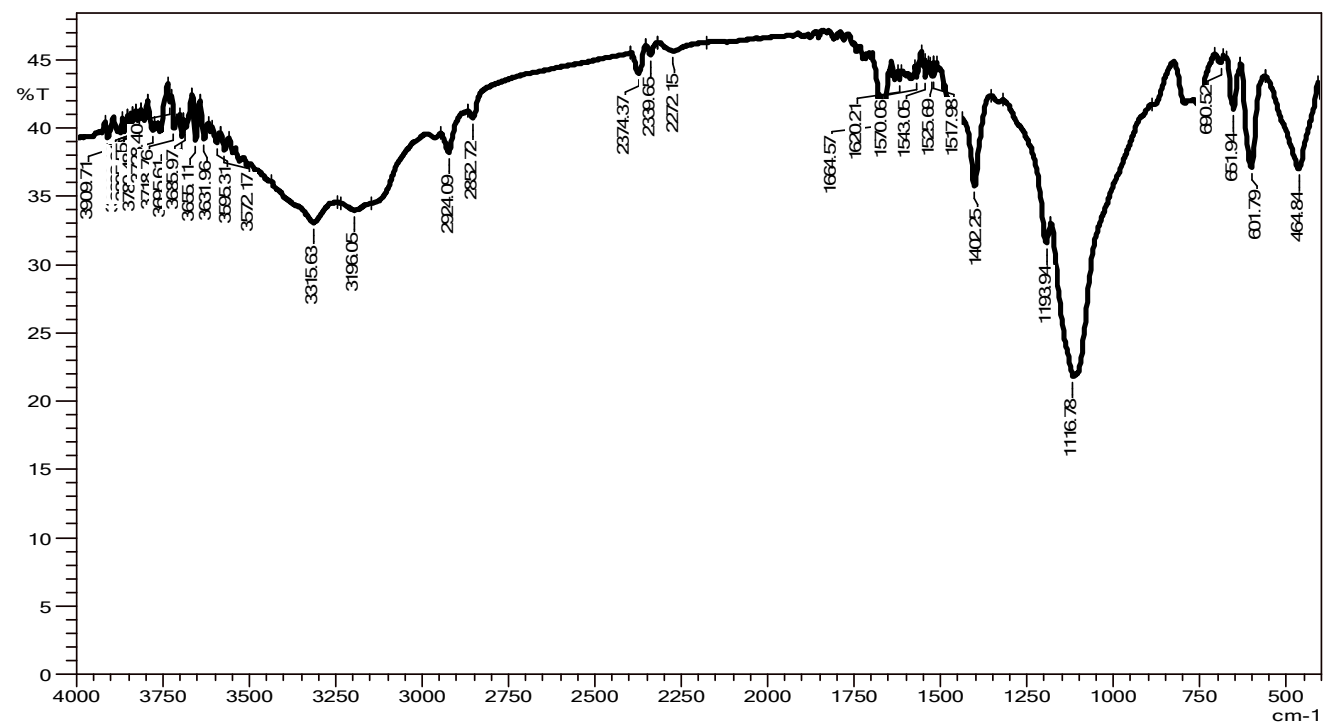

Fig.-8: FTIR Analysis of IF Steel Slag before MB Removal

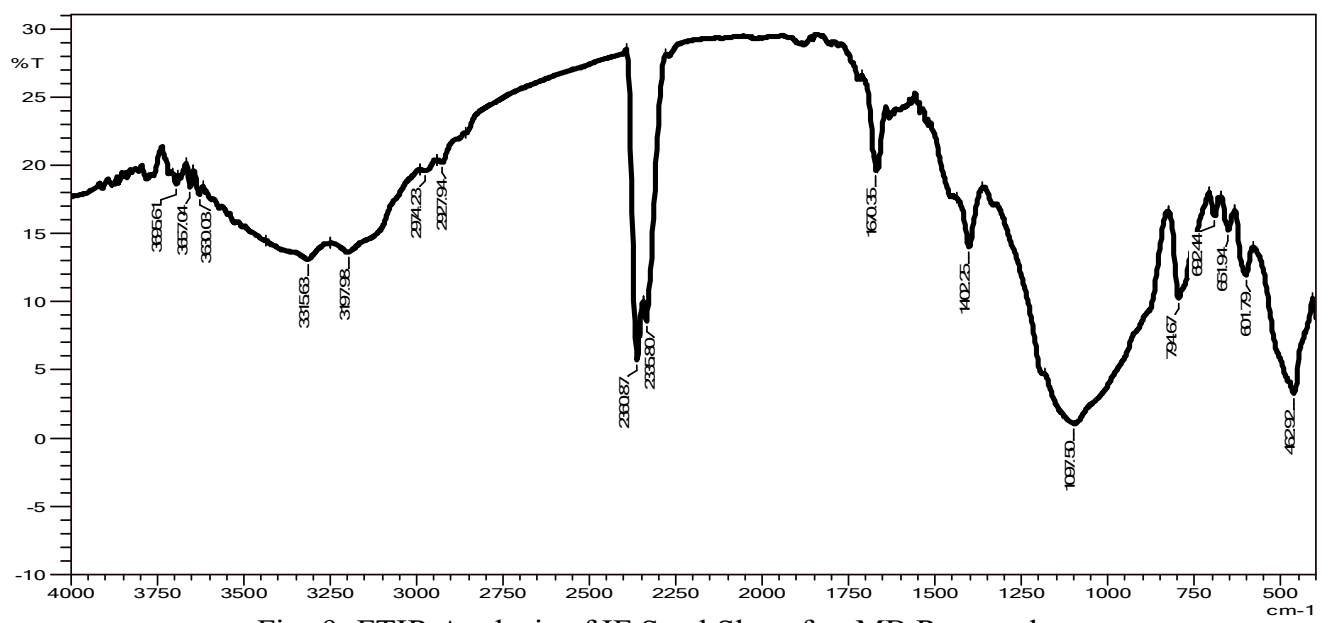

Fig.-9: FTIR Analysis of IF Steel Slag after MB Removal 1019 


\section{CONCLUSION}

This study mainly focuses on the effective utilization of industrial by-product slag, available in large quantities for the removal of textile cationic dye Methylene Blue. Optimization of various parameters such as $\mathrm{pH}$, concentration of adsorbate (MB dye), adsorbent dosage (IF steel slag) and contact time were studied. The maximum removal of $10 \mathrm{mg}$ of MB cationic dye solution is $81.28 \%$ for $5 \mathrm{~g}$ of IF steel slag dosage at $\mathrm{pH}-8$. This process can be scaled up further for the utilization of IF steel slag as a cost-effective adsorbent and it can minimize the toxicity effects of textile industry effluents resulting to a better environment.

\section{ACKNOWLEDGMENT}

We thank the Ministry of Steel, Government of India for the financial support of the project (F.No.11 (1)/SDF/2013-TW) and the management of Sathyabama Institute of Science and Technology, Chennai for its immense support in research activities.

\section{REFERENCES}

1. J. Baalamurugan, V. G. Kumar, K. Govindaraju, B. S. N. Prasad, V. K. B. Raja, R. Padmapriya, International Journal of Nanoscience, 16, 1760013(2017), DOI: $10.1142 / \mathrm{S} 0219581 \mathrm{X} 17600134$

2. R. Padmapriya, V. K. B. Raja, V. G. Kumar, J. Baalamurugan, Rasayan Journal of Chemistry, 12(4) 1744(2019), DOI: 10.31788/RJC.2019.1245211

3. Y. Biskri, D. Achoura, N. Chelghoum, M. Mouret, Construction and Building Materials, 150, 167(2017), DOI:10.1016/j.conbuildmat.2017.05.083

4. R. Padmapriya, V. K. B. Raja, V. G. Kumar, J. Baalamurugan, International Journal of Earth Science and Engineering, 8(5), 2138(2015), DOI:10.1016/j.anucene.2011.08.010

5. A. S. Brand, J. R. Roesler, Cement \& Concrete Composites, 60, 1(2015), DOI:10.1016/j.cemconcomp.2015.04.006

6. Z. Ghouleh, R. I. L. Guthrie, Y. Shao, Journal of $\mathrm{CO}_{2}$ Utilization, 18, 125(2017), DOI:10.1016/j.jcou.2017.01.009

7. M. A. González-Ortega, I. Segura, S. H. P. Cavalaro, B. Toralles-Carbonari, A. Aguado, A. C. Andrello, Constrution and Building Materials, 51, 432(2014), DOI: 10.1016/j.conbuildmat.2013.10.067

8. J. Baalamurugan, V. G. Kumar, S. Chandrasekaran, S. Balasundar, B. Venkatraman, R. Padmapriya, V. K. B. Raja, Journal of Hazardous Materials, 369, 561(2019), DOI:10.1016/j.jhazmat.2019.02.064

9. N. Shao, S. Li, F. Yan, Y. Su, F. Liu, Z. Zhang, Journal of Hazardous Materials, 382, 121120(2020), DOI:10.1016/j.jhazmat.2019.121120

10. N. T. Abdel-Ghani, H. A. Elsayed, S. AbdelMoied, HBRC Journal, 14, 159(2018), DOI: 10.1016/j.hbrcj.2016.06.001

11. X. Gao, M. Okubo, N. Maruoka, H. Shibata, T. Ito, S. Y. Kitamura, Mineral Processing and Extractive Metallurgy, 124(2), 116(2015), DOI:10.1179/1743285514y.0000000068

12. T. A. Mohammed, H. Aa, H. Nf, E. E-A. Ma, E-M. I. Khm, International Journal of Environmental Protection, 2(5), 1(2012),

13. W. M. Mayes, A. L. Riley, H. I. Gomes, P. Brabham, J. Hamlyn, H. Pullin, P. Renforth, Environmental Science \& Technology, 52(14), 7892(2018), DOI:10.1021/acs.est.8b01883

14. M. L. Firdaus, F. E. Madina, S. Y. F, R. Elvia, N. Soraya, D.R. Eddy, A. P. Cid-Andres, Rasayan Journal of Chemistry, 13(1), 249(2020), DOI:10.31788/RJC.2020.1315496

15. N. Barka, M. Abdennouri, M. E. L. Makhfouk, Journal of Taiwan Institute of Chemical Engineers, 42(2), 320(2011), DOI:10.1016/j.jtice.2010.07.004

16. M. Rafatullah, O. Sulaiman, R. Hashim, A. Ahmad, Journal of Hazardous Materials, 177(1-3), 70(2010), DOI:10.1016/j.jhazmat.2009.12.04

17. S. Selvakumar, R. Manivasagan, K. Chinnappan, 3 Biotech, 3(1), 71(2013), DOI:10.1007/s13205012-0073-5

18. S. Dhananasekaran, R. Palanivel, S. Pappu, Journal of Advanced Research, 7(1), 113(2016), 
RASĀYAN J. Chem.

Vol. 13 | No. 2 |1014 - 1021| April - June | 2020

DOI: $10.1016 /$ j.jare.2015.03.003

19. M. S. Mahmoud, HBRC Journal, 12(1), 88(2016), DOI:10.1016/j.hbrcj.2014.07.005

20. M. Daniel, G. D. Luna, E. D. Flores, D. Angela, D. Genuino, C. M. Futalan, M. Wan, Journal of the Taiwan Institute of Chemical Engineers, 44(4), 646(2013), DOI:10.1016/j.jtice.2013.01.010

21. Y. Gao, J. Jiang, S. Tian, K. Li, F. Yan, N. Liu, M. Yang, X. Chen, Scientific Reports, 7(1) 1(2017), DOI: $10.1038 / \mathrm{s} 41598-017-11682-3$

22. M. E. M. Ali, T. A. Gad-Allah, M. I. Badawy, Appled Water Science, 3(1), 263(2013), DOI: $10.1007 / \mathrm{s} 13201-013-0078-1$

23. L. Kang, Y. J. Zhang, L. L. Wang, L. Zhang, K. Zhang, L. C. Liu, Integrated Ferroelectrics An Internationala Journal, 162(1), 8(2015), DOI:10.1080/10584587.2015.1037197

24. F. Ji, C. Li, J. Zhang, L. Deng, Desalination, 269(1-3), 284(2011), DOI:10.1016/j.desal.2010.11.015

25. H. D. Utomo, X. C. Ong, S. M. S. Lim, G. C. B. Ong, P. Li, International Biodeterioration \& Biodegradation, 85, 460(2013), DOI:10.1016/j.ibiod.2012.12.004

26. Rahmi, Ismaturrahmi, I. Mustafa, Microchemical Journal, 144, 397(2019), DOI: 10.1016/j.microc.2018.09.032

27. Y. AM, A-A MM, A. MA, Journal of Analytical \& Bioanalytical Techniques, 5(1), 1(2014), DOI: $10.4172 / 2155-9872.1000179$

28. L. Borah, M. Goswami, P. Phukan, Journal of Environmental Chemical Engineering, 3(2), 1018(2015), DOI: 10.1016/j.jece.2015.02.013

29. Y-B. Kim, J-H. Ahn, International Biodeterioration \& Biodegradation, 95, 208(2014), DOI: 10.1016/j.ibiod.2014.03.023

30. L. V. Tan, L. T. Hung, Rasayan Journal of Chemistry, 9(3), 478(2016).

31. A. Singh, S. Kumar, V. Panghal, S. S. Arya, S. Kumar, Rasayan Journal of Chemistry, 12(4), 1956(2019), DOI:10.31788/RJC.2019.1245401

32. S. M. Ahmed, Canadian Journal of Chemistry, 44(14), 1663(1966), DOI:10.1139/v66-411

[RJC-5715/2020] 